\title{
Influence of Parallel-Joint Position on Mechanical Behavior and Acoustic Emission Characteristics of Rock Pillar
}

\author{
Pei Zhang $\mathbb{D}^{1}{ }^{1}$ Yanpeng He $\mathbb{D}^{1},{ }^{1}$ Zhimeng Sun, ${ }^{2}$ and Dong Yue ${ }^{3}$ \\ ${ }^{1}$ College of Energy Science and Engineering, Xi'an University of Science and Technology, Xi'an 710054, China \\ ${ }^{2}$ Honghui No. 1 Coal Mine of Gansu Jingyuan Coal and Electricity Co., Ltd., Honghui 730699, China \\ ${ }^{3}$ Tongchuan Mining Co., Ltd., Tongchuan 727000, China \\ Correspondence should be addressed to Pei Zhang; zhangpei@xust.edu.cn and Yanpeng He; heyp@stu.xust.edu.cn
}

Received 10 August 2021; Accepted 24 August 2021; Published 2 September 2021

Academic Editor: Gan Feng

Copyright (C) 2021 Pei Zhang et al. This is an open access article distributed under the Creative Commons Attribution License, which permits unrestricted use, distribution, and reproduction in any medium, provided the original work is properly cited.

In this paper, the parallel-joint rock column model is established based on PFC software, and the effects of different joint positions on the mechanical properties, acoustic emission characteristics, and damage evolution characteristics of rock columns are analyzed. In the PFC models, the intact rock is simulated by parallel-bond model, and the joints are simulated by flat-joint contact model. The research result shows that on the whole, when the joint is outside the rock pillar, the UCS of the rock pillar is higher than that of the joint inside the rock pillar, while the elastic modulus is less than that of rock pillar with joint inside. The evolution characteristics of acoustic emission of rock pillars at different joint positions are basically the same. However, the maximum value of acoustic emission events and corresponding deformation of rock pillars at different joint positions are different. The damage of jointed rock mass can generally show three stages: no damage, slow damage increase, and sharp damage increase.

\section{Introduction}

Rock pillars are often reserved to support the excavation space in underground mining, transportation, water conservancy, and other projects [1-3]. However, the stability of these rock pillars is affected by internal joint fissures. Under the condition of special joint location, the bearing capacity of some rock pillars will be reduced, which is easy to cause mine roof disaster or tunnel collapse disaster [4-6]. Therefore, exploring the influence of different joint positions on the stability of rock pillars has important practical engineering value.

At present, many scholars have done a lot of researches on the mechanical properties of jointed rock mass. Bahaaddini et al. [7] used particle flow program (PFC3D) SRM model and studied the effect of joint geometric parameters on the failure mechanism, unconfined compressive strength, deformation modulus, and failure modes of rock mass. The results show that the joint direction and step angle are the main determinants of the failure mode of rock mass, and the joint direction has the greatest influence on the properties of rock mass. Xu et al. [8] reported the plane stress numerical test of embedded partial crossing joints rock mass. The effects of joint position, joint direction, and track length on the mechanical properties are studied. The numerical results show that the failure stress increases with the increase of joint position. When the joint angle is $45^{\circ}$, the compressive strength is the smallest. The compressive strength of partially cut specimens is correlated with the joint trace length using an approximately linear relationship. Kulatilake et al. [9] conducted indoor tests and numerical simulation by using PFC3D and studied the mechanical behavior of model material jointed block under uniaxial load. The influence of joint geometric parameters on the uniaxial compressive strength of joint specimens is studied. The joint geometry is proved to control the failure mode of jointed rock mass under uniaxial loading. Yang et al. [10] studied the peak strength, Young's modulus, and failure mode of brittle-like rock specimens with multiple nonpersistent joints under uniaxial compression. The test results show that the joint angle has the greatest influence on the peak strength and Young's modulus, followed by the joint length. Cao et al. [11] investigated the UCS and failure mode of commonly existing jointed rock specimens by using the 
method of similar material test and PFC2D numerical simulation. The results show that the failure modes of joint specimens under uniaxial compression can be divided into four categories: stepped path failure, plane failure, shear type I failure, and shear type II failure. The failure pattern of the specimen depends on the joint- 1 inclination angle $\alpha$ and the intersection angle $\gamma$ between joint-1 and joint-2, while $\alpha$ strongly affects UCS. These studies are of great value for understanding the failure mechanism and stability of jointed rock pillars. However, there are few systematic studies on the effect of parallel-joint position on the mechanical properties of rock pillar, which has an important impact on the stability of rock pillars.

In addition, a large number of studies have found that rock columns are often accompanied by acoustic emission (AE) in the process of damage and failure. By using acoustic emission characteristics, Lin et al. [12] studied the effect of joint orientation and joint space on rock fragmentation. Liu et al. [13] analyzed the mechanical properties, acoustic emission characteristics, and the relationship between rock mass damage laws and AE based on PFC 3D models. Jiang et al. [14] investigated the acoustic emission characteristic during rock fatigue damage and failure. The research result shows that the AE signal of materials arises from the damage, and the damage variable of rock mass can be established based on AE count, energy, and hits. Zhang et al. [15] discussed the failure and acoustic emission characteristics of jointed rock masses with different joint inclination angles and combination modes. All of the researches show that the stability of rock pillars can be analyzed by AE.

Based on the above researches and with the help of PFC2D numerical model, this paper explores the influence of the position of parallel joints on the mechanical properties and acoustic emission characteristics of rock pillars. In our models, the intact rock and joints are simulated by parallelbond model and flat-joint contact model. In our cognition, there are few studies on the acoustic emission characteristics of rock mass with considering different joint positions. Then, based on the characteristics of AE, the damage evolution of parallel-joint rock pillars is explored. The research results are of great significance for further understanding the stability of rock pillars.

\section{Parallel-Joint Rock Pillar Models}

2.1. Numerical Method. Due to the complexity of geotechnical engineering, conventional numerical simulation methods such as finite element method, finite difference method, and block discrete element method have limitations in the analysis of large deformation and geotechnical failure so that the particle discrete element method (PFC) has been tried and applied in various projects in recent years [16]. PFC program is based on the disk or ball particle generation model and simulates the macro and micro properties of materials through the particles and the bonding properties between particles [17]. In PFC model, two models named contact bond (CB) model and parallel bond (PB) model are usually used to simulate to intact materials [17]. The CB model can transfer tensile and compressive stress, but cannot transfer shear force, so it is suitable to simulate soil materials. The PB model can resist bending moment; it is more suitable to simulate rock mass materials [13]. Meanwhile, in order to simulate joints, PFC provides flat-joint contact model (FJCM), as shown in Figure 1 [17]. By adding FJCM to PBM, the rock pillar model with parallel joints can be made.

2.2. Numerical Model Parameters. The macroscopic mechanical behavior of PFC model needs to be characterized by meso parameters, such as particle mechanical properties and contact bonding properties. Because these meso parameters are difficult to be obtained directly through indoor experiments or field tests, "trial-and-error" method is usually used to obtain them by comparing the results of uniaxial compression and indoor experiments, and the specific check sequence is shown in Figure 2 [18]. Based on this method, Peng and Liu [19] checked the meso parameters of sandstone samples for PFC $2 \mathrm{D}$ model. The meso parameters of sandstone PFC are shown in Table 1. The comparison results of stress-strain curves of sandstone indoor experiment and numerical simulation are shown in Figure 3. It can be seen from the figure that the parameters in Table 1 can better reflect the mechanical properties of complete sandstone. Therefore, the mechanical properties of the complete rock column in this paper are modeled with the parameters in Table 1.

In addition, since it is difficult to obtain the actual mechanical properties of joints through indoor experiments and field tests, this paper uses previous experience [20] to set the mechanical properties of joints to $5 \%$ of the micromechanical properties of intact samples, as shown in Table 2, for modeling.

2.3. Numerical Schemes and Loading Conditions. In order to explore the mechanical behavior and acoustic emission characteristics of rock pillars with parallel joint at different positions, six models as shown in Figure 4 are set. In these models, PBM is used for intact rock mass and FJCM is used for joints. The scale of the model is $50 \mathrm{~mm}$ (length) $\times$ $100 \mathrm{~mm}$ (height). The joint length is $20 \mathrm{~mm}$ and the joint spacing is $2.8 \mathrm{~mm}$. The specific information of parallel-joint location is shown in Table 3. The model first generates PBM and then inserts FJCM. After the model is generated, the displacement loading is carried out by moving the wall at the top of the model, and the loading speed is $0.1 \mathrm{~m} / \mathrm{s}$.

\section{Analysis of Numerical Results}

3.1. Mechanical Properties Analysis. Figure 5 shows the stress-strain of rock pillar with different parallel-joint positions, and Figure 6 shows the UCS and elastic modulus. From these figures, it can be seen that the mechanical properties of rock pillar with different parallel-joint positions are different. When the joint position is on the outsidemiddle, the UCS of the rock pillar is the largest, about 56.2 $\mathrm{MPa}$, while the UCS is the lowest, $38.26 \mathrm{MPa}$, when the joint position is on the inside-bottom of the rock pillar. On 


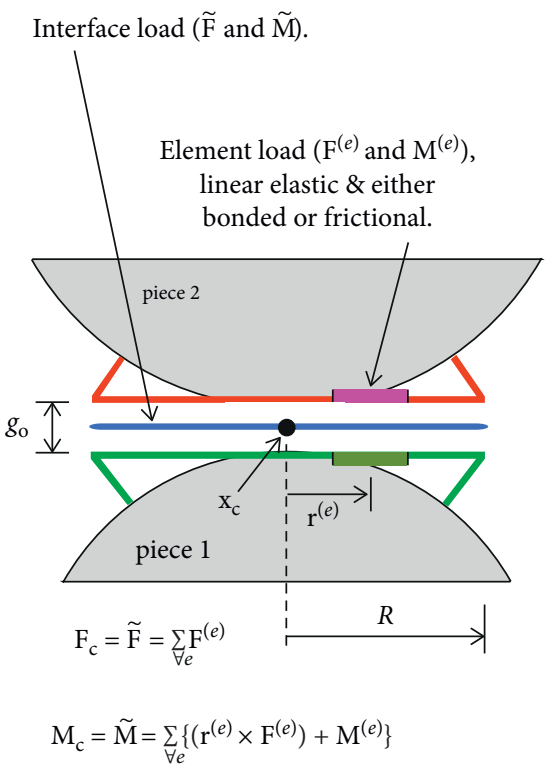

notional-surface element

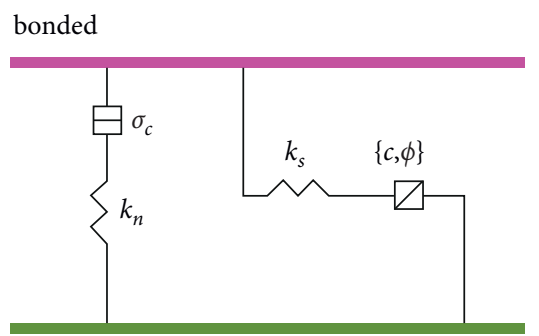

unbonded

FIgURE 1: Flat-joint contact model [17].

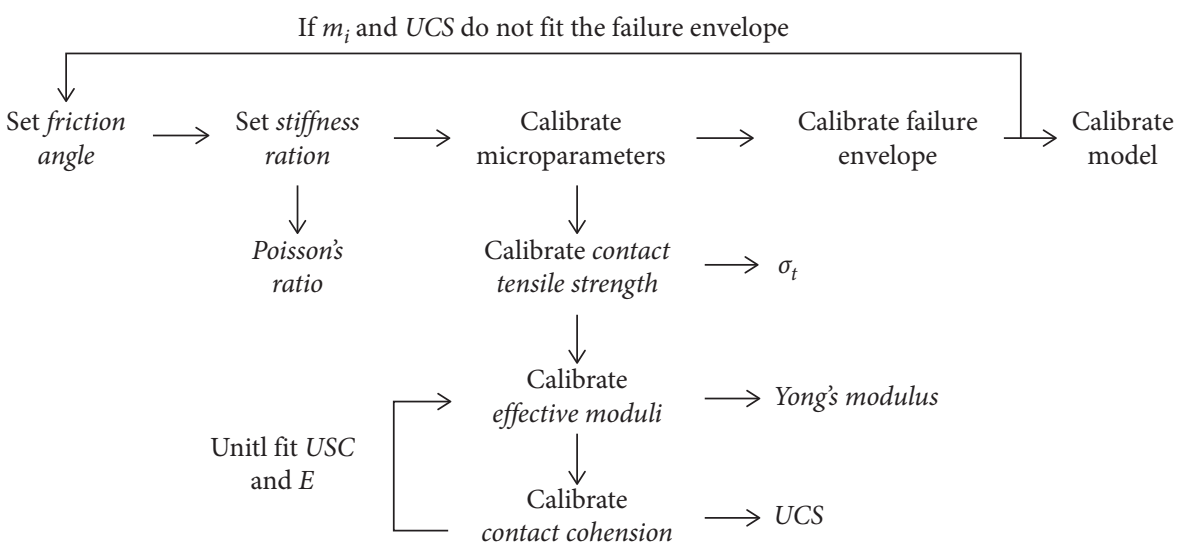

FIgURE 2: Calibration procedure provided by Castro-Filgueira [12].

TABLE 1: Physicomechanical parameters of PFC 2D test model [19].

\begin{tabular}{lc}
\hline Parameter & Value \\
\hline Minimum particle diameter $(\mathrm{mm})$ & 0.3 \\
Maximum particle diameter $(\mathrm{mm})$ & 0.5 \\
Contact modulus of the particle $(\mathrm{GPa})$ & 10.2 \\
Parallel-bond deformation modulus $(\mathrm{GPa})$ & 16.2 \\
Contact bond gap $(\mathrm{mm})$ & 0.05 \\
Porosity & 0.1 \\
Density $\left(\mathrm{kg} / \mathrm{m}^{3}\right)$ & 2500 \\
Parallel-bond tensile strength $(\mathrm{MPa})$ & 22 \\
Parallel-bond cohesive force $(\mathrm{MPa})$ & 56.5 \\
Stiffness ratio & 1.51 \\
\hline
\end{tabular}

the whole, when the joint is outside the rock pillar, the UCS of the rock pillar is higher than that of the joint inside the rock pillar. The elastic modulus of rock pillar with paralleljoint outside itself is less than the rock pillar with paralleljoint inside itself. The largest value of elastic modulus of rock pillar is when the joint on inside-top of rock pillar,
12.14 GPa, and the lowest value is when the joint on outsidetop of rock pillar, $11.56 \mathrm{GPa}$. On the whole, the difference of elastic modulus of rock pillar with different parallel-joint positions is not very large, about $0.58 \mathrm{GPa}$.

3.2. AE Characteristics Analysis. Since acoustic emission monitoring plays an important role in engineering stability evaluation, it is of great significance to analyze the acoustic emission characteristics of rock pillar at different joint positions in this section. The mechanism of acoustic emission is the crack propagation in rock mass caused by external energy, which is a physical phenomenon of crack fracture. In PFC model, the fracture of the parallel bond will release a certain amount of elastic energy. Therefore, the fracture of the parallel bond can be used to reflect the acoustic emission of rock mass [19]. In this paper, the AE events of different rock pillars are analyzed based on the number of bonds breakages. Figure 7 shows the AE characteristics of rock pillar with different parallel-joint 


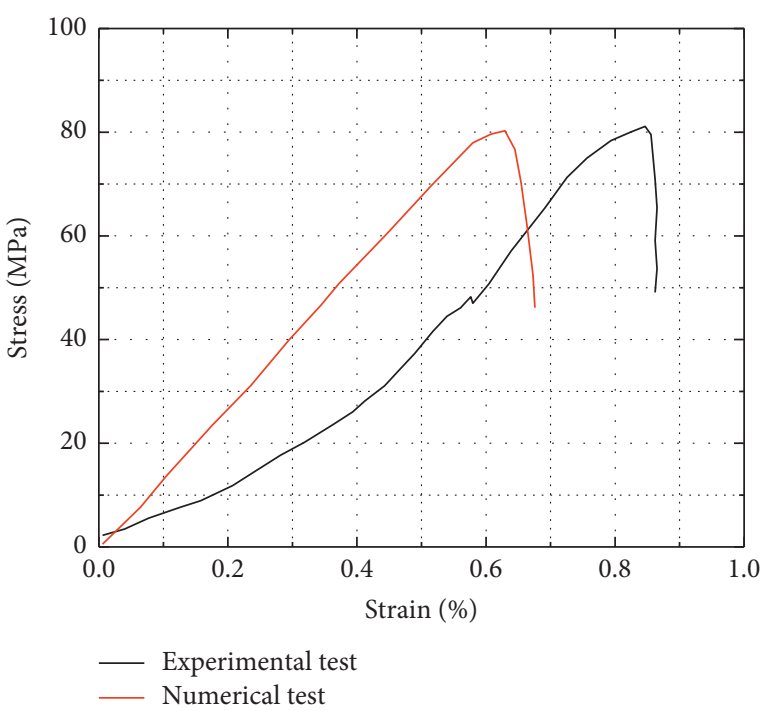

Figure 3: Stress-strain curves of real sandstone and PFC 2D model [19].

TABLE 2: Physicomechanical parameters of FJCM.

\begin{tabular}{lc}
\hline Parameter & Value \\
\hline Joint tensile strength $(\mathrm{MPa})$ & 1.1 \\
Joint cohesive force $(\mathrm{MPa})$ & 2.8 \\
Joint friction coefficient & 0.3 \\
Joint normal stiffness $(\mathrm{GPa} / \mathrm{m})$ & 1 \\
Joint tangential stiffness $(\mathrm{GPa} / \mathrm{m})$ & 0.5 \\
Joint width $(\mathrm{mm})$ & 1 \\
\hline
\end{tabular}

positions. It can be seen from the figure that with the continuous increase of stress, the number of acoustic emission events presents a process of none-slow increasesharp increase. At the initial stage of the compression process, because the numerical rock pillar does not consider the damage inside the rock mass (except a group of joints), there are no acoustic emission events under the action of small stress. With the continuous increase of stress, micro cracks appear in the rock mass, and the acoustic emission events of rock pillars increase slowly. In this process, the interior of the rock pillar is gradually damaged, but it does not reach the failure strength. Subsequently, a large number of acoustic emission events occurred near the peak strength of rock mass, that is, before and after rock mass failure. There may be multiple peaks of acoustic emission events. It can be seen that acoustic emission events are accompanied by rock mass damage, which is consistent with the previous researches [12-15].

The evolution characteristics of acoustic emission of rock pillars at different joint positions are basically the same, which goes through the process of none-slow increase-sharp increase. There may be multiple peaks of acoustic emission events. However, the maximum value of acoustic emission events and corresponding deformation of rock pillars at different joint positions are different. When the position of parallel-joint on the outside-middle of rock pillar, the event of the acoustic emission events is the most, about 65 times, followed by when parallel joint is on outside-top, outside- bottom, and inside-middle of rock pillar, around 30 times. Finally, when the parallel-joint positions are on the insidetop and inside-bottom positions, the acoustic emission event is the lowest, about 25 times or below. For the strain corresponding to the maximum acoustic emission event, the deformation of condition \#2 is the largest, followed by conditions \#1 and \#3 and then conditions \#4, \#5, and \#6. That is, when the joint is inside the rock pillar, the deformation of rock mass failure is less than that when the joint is outside the rock pillar.

3.3. Failure Modes Analysis. Figure 8 presents the failure modes of rock pillar with different parallel-joint positions. The failure modes of rock pillars at different parallel-joint positions are different. When the joint position is working condition \#1, the failure of rock pillar is mainly in the upper left corner. When the joint position is the working condition $\# 2$, the failure of rock pillar is the whole pillar through failure, with the top in the upper right corner and the bottom in the middle of the pillar. When the joint position is the working condition \#3, the failure of the rock pillar is mainly in the middle of the bottom and connected with the joint failure on the left. When the joint position is the working condition \#4, the failure of the rock pillar is mainly at the top of the rock pillar (near the left), accompanied by the through failure in the rock pillar. When the joint position is working condition $\# 5$, the failure of rock pillar is through the top joint of rock pillar and the bottom of rock pillar (on the right). When the joint position is the working condition \#6, the failure of the rock pillar is mainly at the bottom (to the right), accompanied by the through failure in the rock pillar. Generally, when the joint is at the top or bottom of the rock pillar, the instability of the rock pillar is mainly due to the accumulation of cracks at the top or bottom and the penetration failure with the joint. When the joint is in the center of the rock pillar, the instability of the rock pillar is the overall penetration failure of the connecting joints. The practical engineering can grasp this basic information to strengthen the rock pillar.

\section{Damage Evolution of Parallel-Joint Rock Pillars Based on AE Events}

A large number of studies show that acoustic emission events can be used to define damage variables and then study the damage evolution characteristics of rock mass [21, 22]. The damage variables based on acoustic emission characteristics can be defined as follows:

$$
D=\frac{C_{i}}{C}
$$

where $C_{i}$ represents the acoustic emission event cumulative times when rock damaged in a certain time and $C$ represents the acoustic emission event cumulative times when rock damaged completely.

Figure 9 shows the damage evolution characteristics of rock pillar with different parallel-joint positions. It can be seen from the figure that the damage of jointed rock mass 


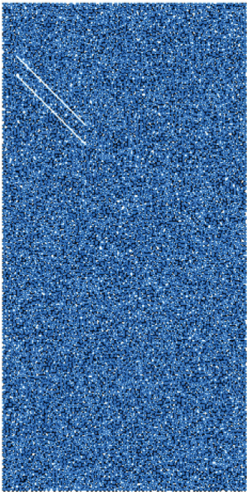

(a)

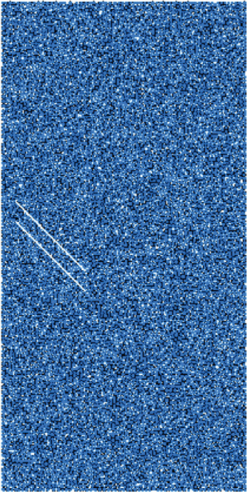

(b)

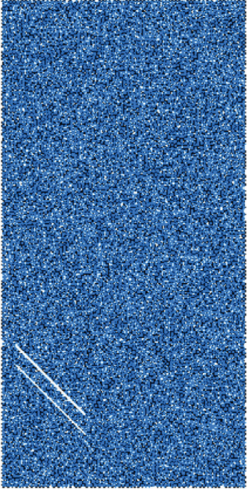

(c)

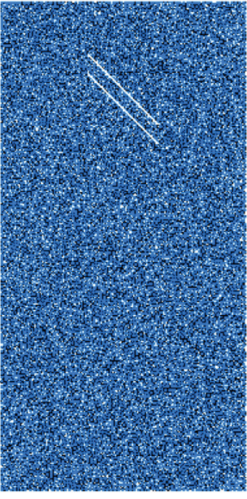

(d)

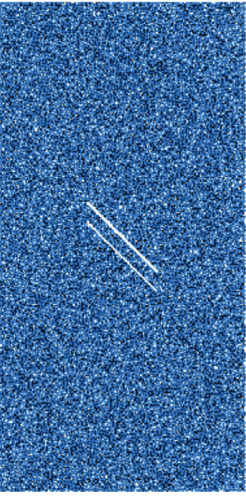

(e)

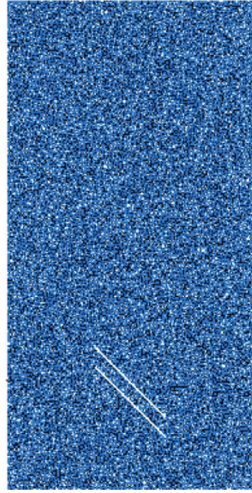

(f)

Figure 4: Numerical parallel-joint rock models. (a) \#1. (b) \#2. (c) \#3. (d) \#4. (e) \#5. (f) \#6.

TABLE 3: Information of numerical parallel-joint rock models.

\begin{tabular}{lcccc}
\hline Joint ID & Joint positions & Position description & Joint length $(\mathrm{mm})$ & Joint spacing $(\mathrm{mm})$ \\
\hline$\# 1$ & $(-15 \mathrm{~mm}, 30 \mathrm{~mm})$ & Outside-top & 20 & 2.8 \\
$\# 2$ & $(-15 \mathrm{~mm}, 0 \mathrm{~mm})$ & Outside-middle & 20 & 2.8 \\
$\# 3$ & $(-15 \mathrm{~mm},-30 \mathrm{~mm})$ & Outside-bottom & 20 & 2.8 \\
$\# 4$ & $(0 \mathrm{~mm}, 30 \mathrm{~mm})$ & Inside-top & 20 & 2.8 \\
$\# 5$ & $(0 \mathrm{~mm}, 0 \mathrm{~mm})$ & Inside-middle & 20 & 2.8 \\
$\# 6$ & $(0 \mathrm{~mm},-30 \mathrm{~mm})$ & Inside-bottom & & 2.8 \\
\hline
\end{tabular}

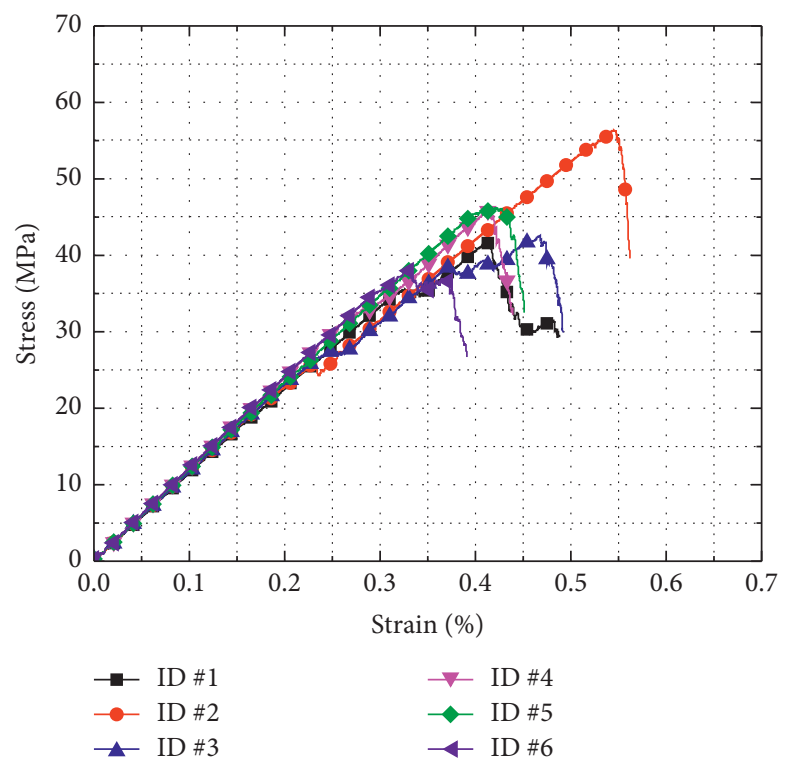

FIGURE 5: Stress-strain of rock pillar with different parallel-joint positions.

can generally show three stages: no damage, slow damage increase, and sharp damage increase. This corresponds to the three stages of acoustic emission evolution. At the same time, there are multiple trapezoidal step stages at slow increase stage. The damage evolution characteristics of rock pillars are different with different joint positions. It is mainly reflected in the following aspects: first, the increase rate (slope of the strain-D curves) in the slow increase stage is different. The growth rate of working conditions 1, 3 and 4 is faster at this stage, while the increase rate of other working conditions is slightly moderate. Second, in the sharp increase stage, the increase rate of working conditions 2, 5, and 6 is the largest, while other working conditions are slightly relieved. For working conditions 1, 3, and 4 , since they have the obvious damage fluctuation characteristics at the stage of slow increase, it is an important signal feature for rock pillar stability analysis. For other working conditions, due to the lack of this signal feature, the prediction signal for rock stability is weak, so the actual project should be more careful. 


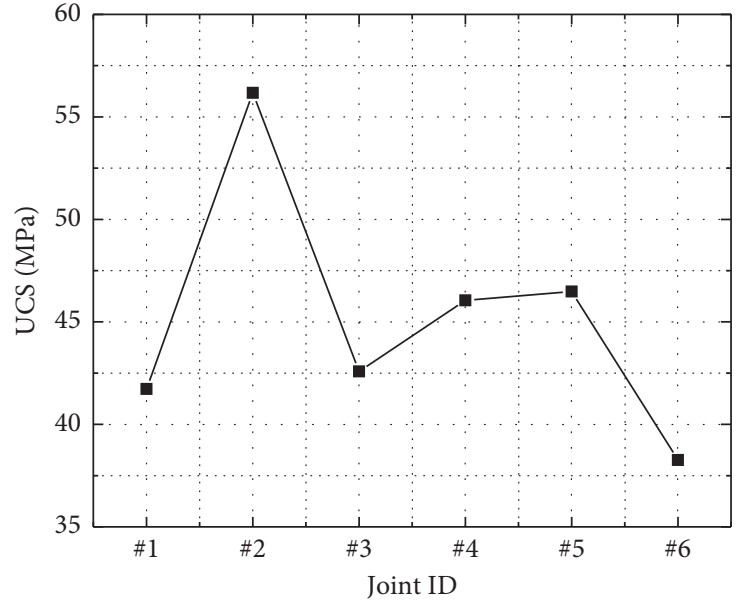

(a)

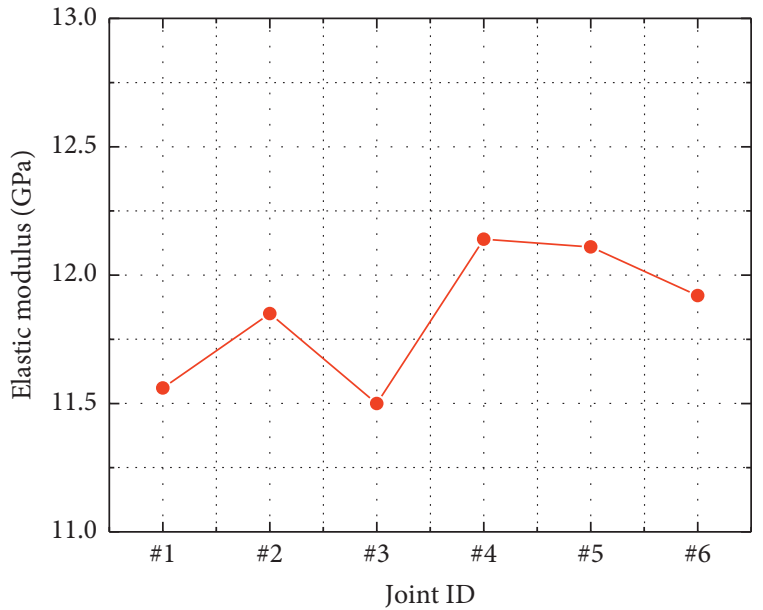

(b)

FIGURE 6: UCS and elastic modulus of rock pillar with different parallel-joint positions.

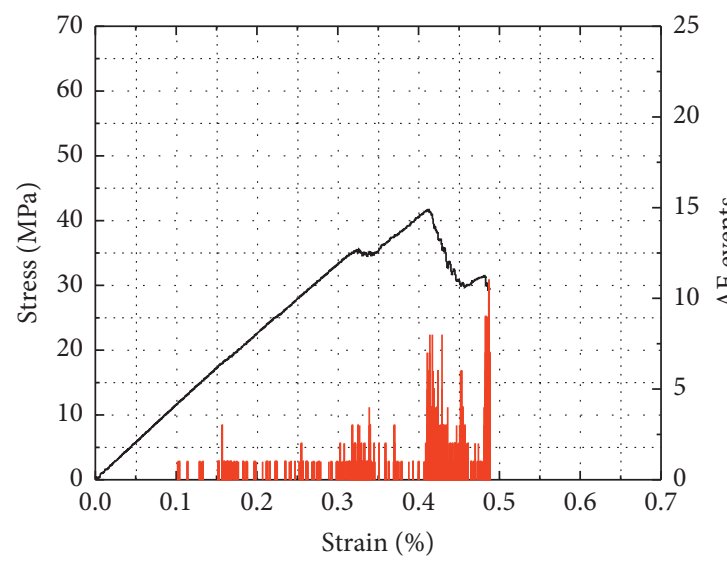

- Stress

$\mathrm{AE}$

(a)

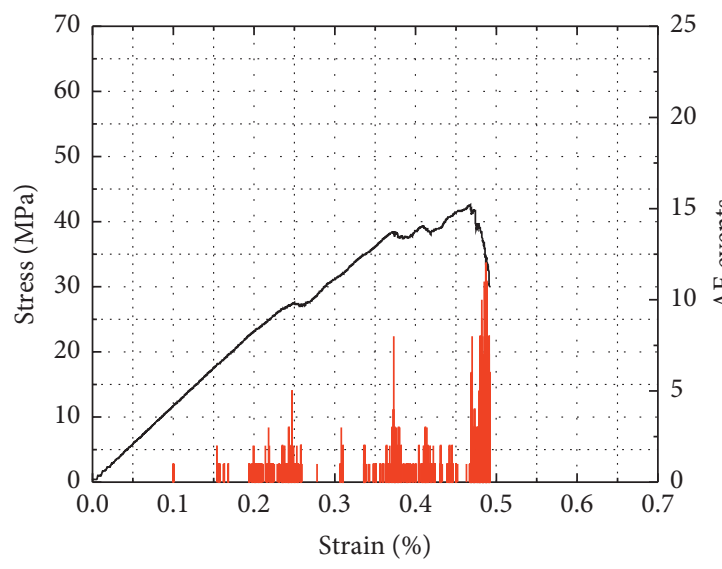

— Stress

$\mathrm{AE}$

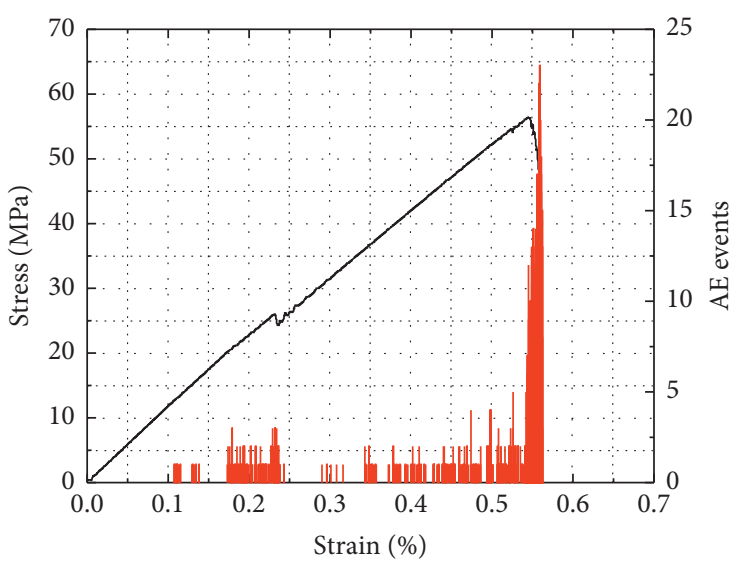

- Stress

$\mathrm{AE}$

(b)

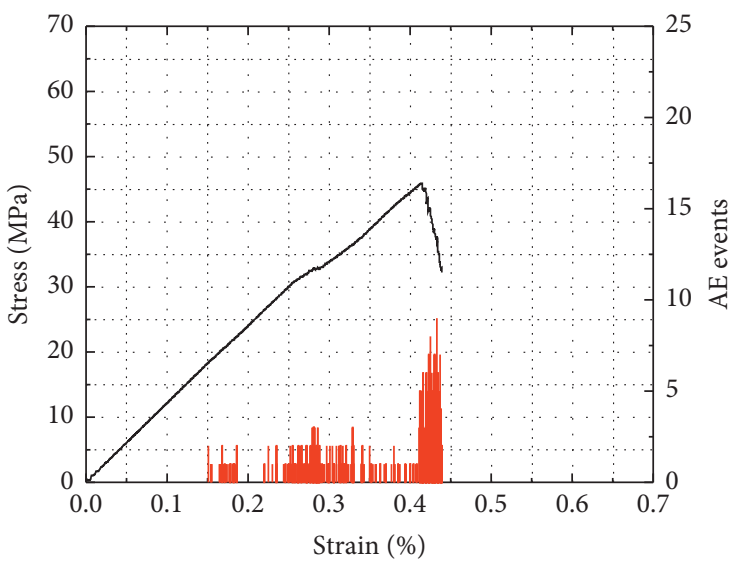

- Stress

$\mathrm{AE}$

(c)

(d)

Figure 7: Continued. 


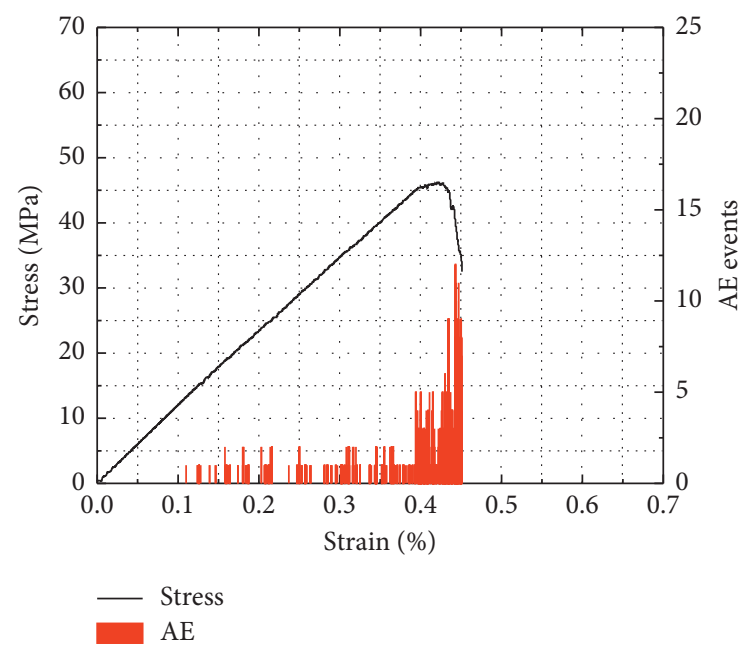

(e)

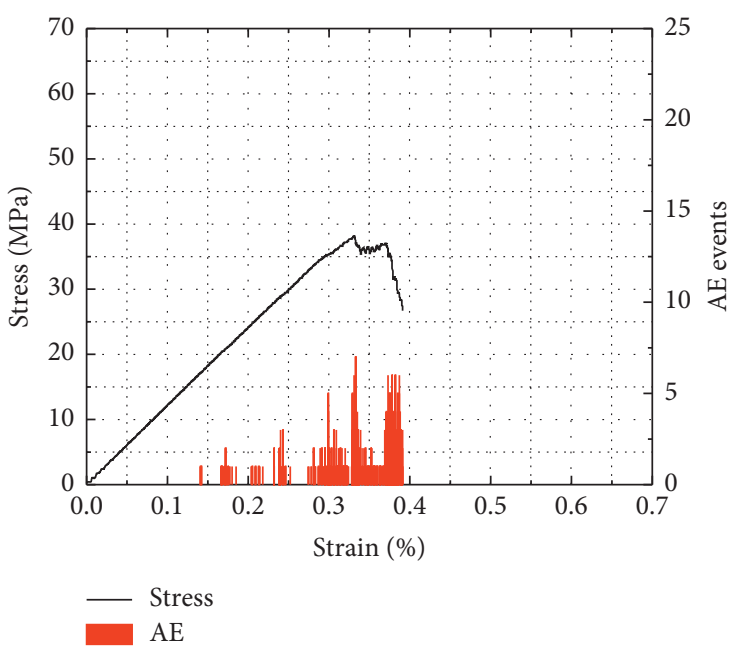

(f)

Figure 7: AE characteristics of rock pillar with different parallel-joint positions. (a) \#1. (b) \#2. (c) \#3. (d) \#4. (e) \#5. (f) \#6.

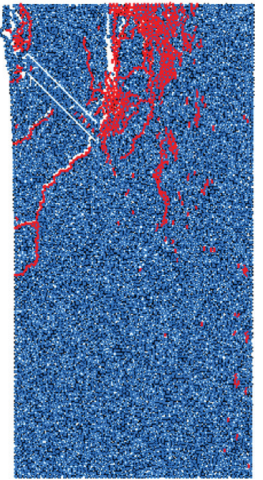

(a)

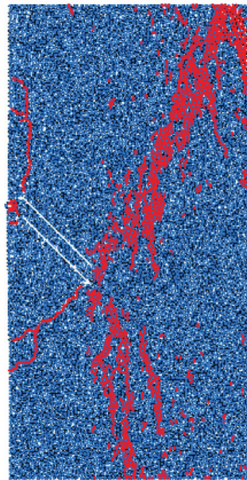

(b)

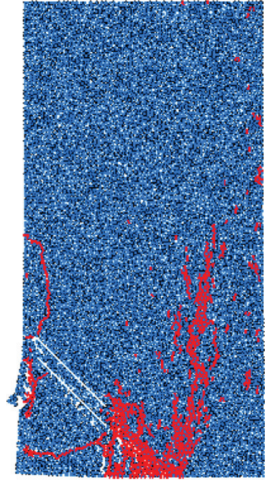

(c)

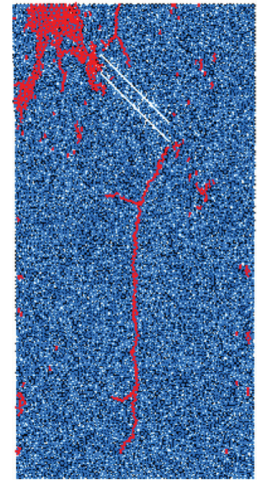

(d)

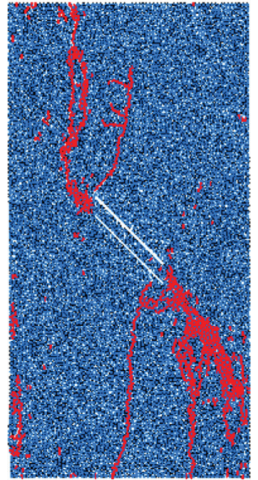

(e)

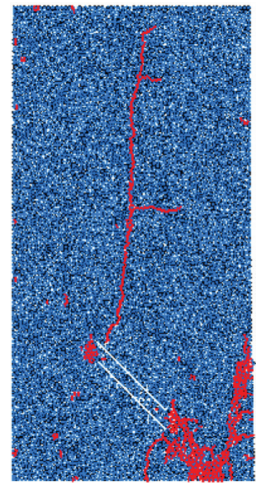

(f)

Figure 8: Failure modes of rock pillar with different parallel-joint positions. (a) \#1. (b) \#2. (c) \#3. (d) \#4. (e) \#5. (f) \#6.

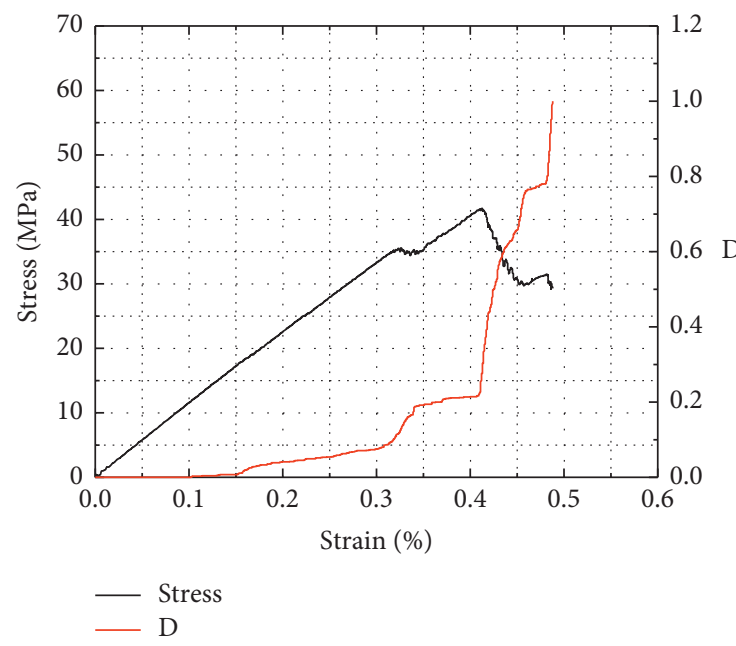

(a)

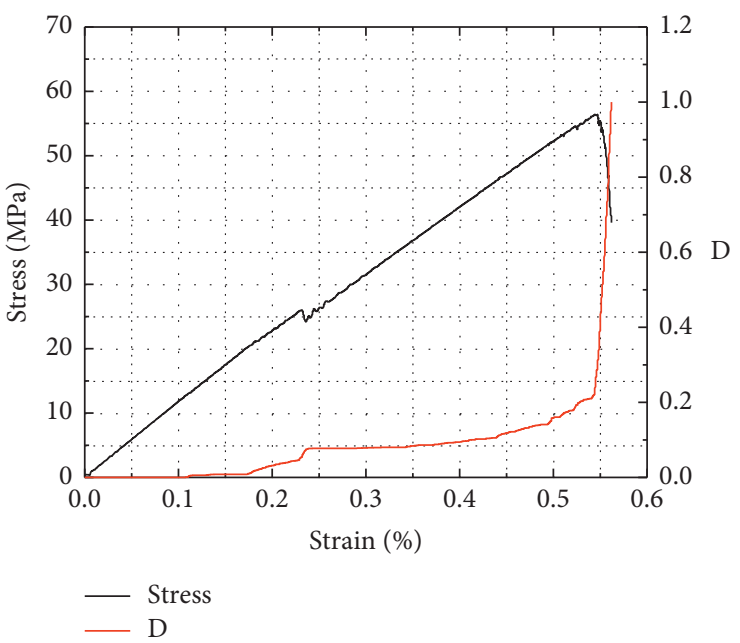

(b)

FIgURE 9: Continued. 


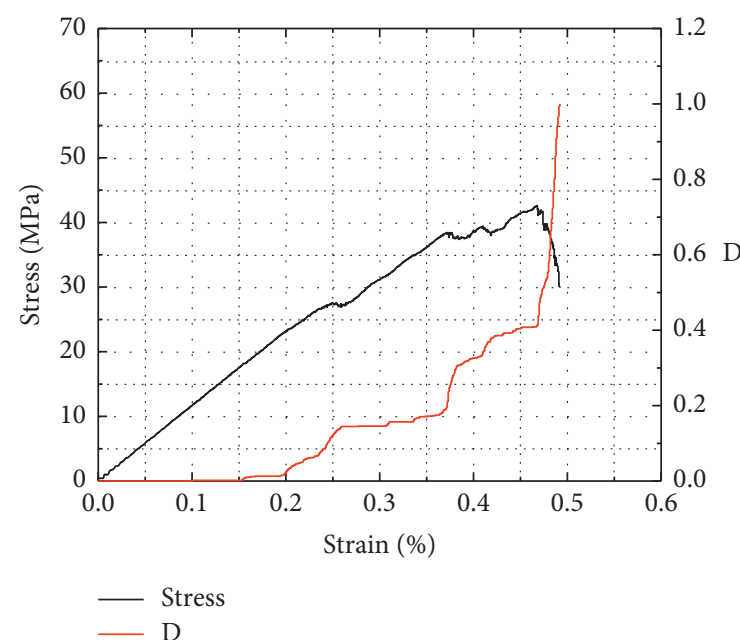

(c)

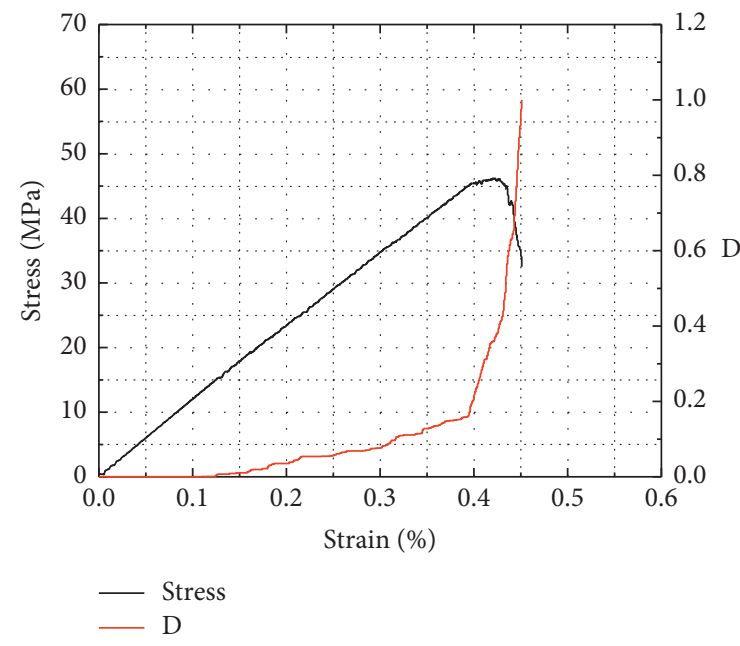

(e)

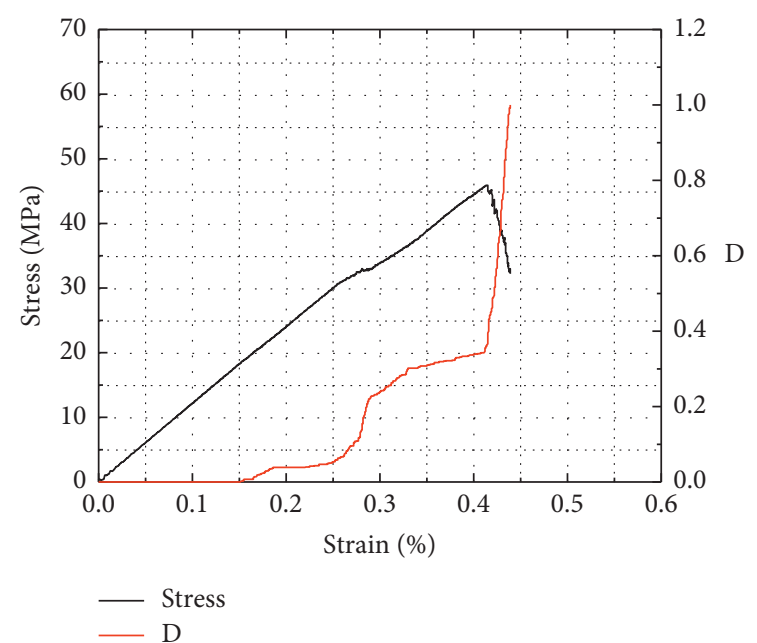

(d)

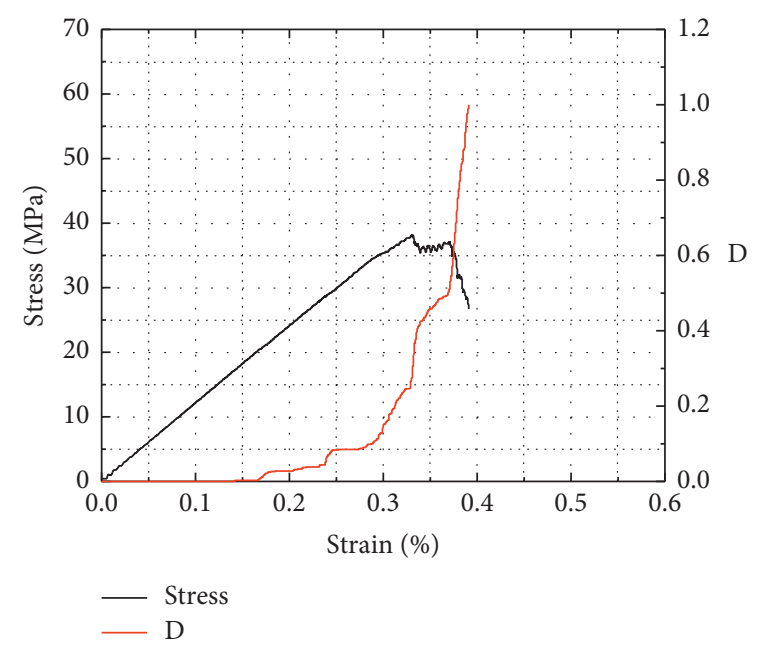

(f)

Figure 9: Damage evolution characteristics of rock pillar with different parallel-joint positions. (a) \#1. (b) \#2. (c) \#3. (d) \#4. (e) \#5. (f) \#6.

\section{Conclusions}

Based on the PFC model, this paper analyzed the influence of the parallel-joint positions on the mechanical properties and acoustic emission characteristics of rock pillars and obtains the following main conclusions.

The mechanical properties of rock pillar with different parallel-joint positions are different. On the whole, when the joint is outside the rock pillar, the UCS of the rock pillar is higher than that of the joint inside the rock pillar. The elastic modulus of rock pillar with parallel-joint outside itself is less than the rock pillar with parallel-joint inside itself. However, the difference of elastic modulus of rock pillar with different parallel-joint positions is not very large.

With the continuous increase of stress, the number of acoustic emission events presents a process of none-slow increase-sharp increase. The evolution characteristics of acoustic emission of rock pillars at different joint positions are basically the same. However, the maximum value of acoustic emission events and corresponding deformation of rock pillars at different joint positions are different. When the position of parallel-joint on the outside-middle of rock pillar, the events of the acoustic emission events is the most, followed by when parallel-joint on outside-top, outside-bottom, and inside-middle of rock pillar. For the strain corresponding to the maximum acoustic emission event, the deformation of condition \#2 is the largest, followed by conditions \#1 and \#3.

The failure modes of rock pillars at different paralleljoint positions are different. Generally, when the joint is at the top or bottom of the rock pillar, the instability of the rock pillar is mainly due to the accumulation of cracks at the top or bottom and the penetration failure with the joint. When the joint is in the center of the rock pillar, the instability of the rock pillar is the overall penetration failure of the connecting joints. The practical engineering can grasp this basic information to strengthen the rock pillar.

The damage of jointed rock mass can generally show three stages: no damage, slow damage increase, and sharp damage increase. This corresponds to the three stages of acoustic emission evolution. The damage evolution 
characteristics of rock pillars are different with different joint positions. First, the increase speed in the slow increase stage is different. The growth rate of working conditions 1,3 , and 4 is faster at this stage, while the growth rate of other working conditions is slightly moderate. Second, in the sharp increase stage, the growth rate of working conditions 2,5 , and 6 is the largest, while other working conditions are slightly relieved.

\section{Data Availability}

The datasets generated and analyzed in the current study may be obtained from the corresponding author upon reasonable request.

\section{Disclosure}

The authors would like to declare that the work described herein is original research and has not been previously published.

\section{Conflicts of Interest}

The authors declare no conflicts of interest.

\section{Authors' Contributions}

All authors approved this study for publication.

\section{Acknowledgments}

The authors gratefully acknowledge the funding provided by the Science and Technology Department Joint Fund Project (Grant no. LH[2017]7036).

\section{References}

[1] Q. Wang, M. C. He, S. C. Li et al., "Comparative study of model tests on automatically formed roadway and gob-side entry driving in deep coal mines," International Journal of Mining Science and Technology, vol. 31, no. 4, pp. 591-601, 2021.

[2] F. Gan, Y. Kang, X.-C. Wang, Y. Hu, and X. Li, "Investigation on the failure characteristics and fracture classification of shale under Brazilian test conditions," Rock Mechanics and Rock Engineering, vol. 53, no. 7, pp. 3325-3340, 2020.

[3] C. Zhu, M. C. He, X. H. Zhang, Z. G. Tao, Q. Yin, and L. F. Li, "Nonlinear mechanical model of constant resistance and large deformation bolt and influence parameters analysis of constant resistance behavior," Rock and Soil Mechanics, vol. 42, no. 7, pp. 1911-1924.

[4] Y. Zhang, D. Stead, and D. Elmo, "Characterization of strength and damage of hard rock pillars using a synthetic rock mass method," Computers and Geotechnics, vol. 65, pp. 56-72, 2015.

[5] Q. Yin, J. Wu, C. Zhu, M. He, Q. Meng, and H. Jing, "Shear mechanical responses of sandstone exposed to high temperature under constant normal stiffness boundary conditions," Geomechanics and Geophysics for Geo-Energy and GeoResources, vol. 7, no. 2, p. 35, 2021.

[6] Q. Wang, Y. Wang, M. He et al., "Experimental research and application of automatically formed roadway without advance tunneling," Tunnelling and Underground Space Technology, vol. 114, Article ID 103999, 2021.
[7] M. Bahaaddini, G. Sharrock, and B. K. Hebblewhite, "Numerical investigation of the effect of joint geometrical parameters on the mechanical properties of a non-persistent jointed rock mass under uniaxial compression," Computers and Geotechnics, vol. 49, pp. 206-225, 2013.

[8] T. Xu, P. G. Ranjith, P. L. P. Wasantha, J. Zhao, C. A. Tang, and W. C. Zhu, "Influence of the geometry of partially-spanning joints on mechanical properties of rock in uniaxial compression," Engineering Geology, vol. 167, pp. 134-147, 2013.

[9] P. H. S. W. Kulatilake, B. Malama, and J. Wang, "Physical and particle flow modeling of jointed rock block behavior under uniaxial loading," International Journal of Rock Mechanics and Mining Sciences, vol. 38, no. 5, pp. 641-657, 2001.

[10] W. Yang, G. Li, P. Ranjith, and L. Fang, "An experimental study of mechanical behavior of brittle rock-like specimens with multi-non-persistent joints under uniaxial compression and damage analysis," International Journal of Damage Mechanics, vol. 28, no. 10, pp. 1490-1522, 2019.

[11] R.-h. Cao, P. Cao, X. Fan, X. Xiong, and H. Lin, "An experimental and numerical study on mechanical behavior of ubiquitous-joint brittle rock-like specimens under uniaxial compression," Rock Mechanics and Rock Engineering, vol. 49, no. 11, pp. 4319-4338, 2016.

[12] Q.-b. Lin, P. Cao, K.-h. Li, R.-h. Cao, K.-p. Zhou, and H.-w. Deng, "Experimental study on acoustic emission characteristics of jointed rock mass by double disc cutter," Journal of Central South University, vol. 25, no. 2, pp. 357-367, 2018.

[13] W. Liu, J. Liu, and C. Zhu, "Multi-scale effect of acoustic emission characteristics of 3D rock damage," Arabian Journal of Geosciences, vol. 12, no. 22, pp. 1-13, 2019.

[14] X. Jiang, L. Shu-Chun, T. Yun-Qi, T. Xiao-jun, and W. Xin, "Acoustic emission characteristic during rock fatigue damage and failure," Procedia Earth and Planetary Science, vol. 1, no. 1, pp. 556-559, 2009.

[15] Q. Zhang, X. Tang, Y. Zhou, and D. Ma, "Failure and acoustic emission characteristics of jointed rock masses with different joint inclination angles and combination mode," Geotechnical \& Geological Engineering, pp. 1-11, 2021.

[16] C. Shi, Q. Zhang, and S. Wang, Numerical Simulation Technology and Application with Particle Flow Code (PFC5.0, China construction industry press, Beijing, China, 2018.

[17] Itasca Consulting Group, PFC Users' Manual (version 5.0), Minnestota: Inc., Duluth, MN, USA, 2014.

[18] U. Castro-Filgueira, L. R. Alejano, J. Arzúa, and D. M. Ivars, "Sensitivity analysis of the micro-parameters used in a PFC analysis towards the mechanical properties of rocks," Procedia Engineering, vol. 191, pp. 488-495, 2017.

[19] C. Peng and W. Liu, "Study on pressure relief effect of rock mass with different borehole parameters," Advances in Civil Engineering, vol. 2021, Article ID 5558673, 15 pages, 2021.

[20] P. Wang, M. Cai, F. Ren, C. Li, and T. Yang, "A digital imagebased discrete fracture network model and its numerical investigation of direct shear tests," Rock Mechanics and Rock Engineering, vol. 50, no. 7, pp. 1801-1816, 2017.

[21] X. Yan, L. Jun, and L. Gonghui, "Mechanical properties and acoustic emission properties of rocks with different transverse scales," Shock and Vibration, vol. 2017, Article ID 3853276, 8 pages, 2017.

[22] B. X. Liu, J. L. Huang, Z. Y. Wang, and L. Liu, "Study on damage evolution and acoustic emission character of coalrock under uniaxial compression," Chinese Journal of Rock Mechanics and Engineering, vol. 28, no. 1, pp. 3234-3238, 2009. 